\title{
Endocytosis, Signaling, and Beyond
}

\author{
Pier Paolo Di Fiore ${ }^{1,2}$ and Mark von Zastrow ${ }^{3,4}$ \\ ${ }^{1}$ Department of Experimental Oncology, Istituto Europeo di Oncologia, 20141 Milan, Italy \\ ${ }^{2}$ Dipartimento di Scienze della Salute, Università degli Studi di Milano, 20122 Milan, Italy \\ ${ }^{3}$ Department of Psychiatry, University of California San Francisco School of Medicine, San Francisco, \\ California 94158 \\ ${ }^{4}$ Department of Cellular \& Molecular Pharmacology, University of California San Francisco School \\ of Medicine, San Francisco, California 94158 \\ Correspondence: pierpaolo.difiore@ieo.eu; mark.vonzastrow@ucsf.edu
}

\begin{abstract}
The endocytic network comprises a vast and intricate system of membrane-delimited cell entry and cargo sorting routes running between biochemically and functionally distinct intracellular compartments. The endocytic network caters to the organization and redistribution of diverse subcellular components, and mediates appropriate shuttling and processing of materials acquired from neighboring cells or the extracellular milieu. Such trafficking logistics, despite their importance, represent only one facet of endocytic function. The endocytic network also plays a key role in organizing, mediating, and regulating cellular signal transduction events. Conversely, cellular signaling processes tightly control the endocytic pathway at different steps. The present article provides a perspective on the intimate relationships that exist between particular endocytic and cellular signaling processes in mammalian cells, within the context of understanding the impact of this nexus on integrated physiology.
\end{abstract}

M olecular mechanisms governing the remarkable diversity of endocytic routes and trafficking steps are described elsewhere in the literature (see Bissig and Gruenberg 2013; Henne et al. 2013; Burd and Cullen 2014; Gautreau et al. 2014; Kirchhausen et al. 2014; Mayor et al. 2014; Merrifield and Kaksonen 2014; Piper et al. 2014). Moreover, these have been the focus of many studies in the last 30 years, and the topic has been covered by many excellent reviews, making it unnecessary for us to dwell on this aspect any further here (see, for instance, Howes et al. 2010; McMahon and Boucrot 2011; Sandvig et al. 2011; Parton and del Pozo 2013). Herein, we will instead concentrate our attention on how cellular regulatory mechanisms control endocytosis, as well as on how endocytic events impinge on cell functions. Emphasis will be placed, although not exclusively, on studies that analyze cellular networks using holistic approaches and in vivo analysis. Our aim is to give the reader a flavor of the deep embedding of endocytic processes within cellular programs, a concept we refer to as the endocytic matrix (Scita and Di Fiore 2010).

Editors: Sandra L. Schmid, Alexander Sorkin, and Marino Zerial

Additional Perspectives on Endocytosis available at www.cshperspectives.org

Copyright (C) 2014 Cold Spring Harbor Laboratory Press; all rights reserved; doi: 10.1101/cshperspect.a016865

Cite this article as Cold Spring Harb Perspect Biol 2014;6:a016865 
P.P. Di Fiore and M. von Zastrow

\section{CELLULAR PROGRAMS REGULATING THE ENDOCYTIC PATHWAY: HIGH- THROUGHPUT STUDIES AND IN SILICO ANALYSIS OF CELLULAR REGULATORY NETWORKS}

If we reflect on the pervasiveness of the endocytic network throughout the cell, we must inevitably infer that any perturbations in this system will likely have unpredictable and critical effects on cellular homeostasis (Sigismund et al. 2012). High-throughput studies of endocytic pathways have helped to characterize this complex regulatory network, paving the way for us to finally understand in molecular terms the true extent of the impact of endocytosis on cellular homeostasis, and the reciprocal modulation of endocytosis by signaling and metabolic pathways (Pelkmans et al. 2005; Snijder et al. 2009, 2012; Collinet et al. 2010; Lupberger et al. 2011; Mercer et al. 2012). For example, recent work has shown that different signaling events or stress responses can cause specific remodeling of endocytic compartments through the direct or indirect activation of defined endocytic pathways. Among these compartments, endosomes have emerged as critical endocytic regulatory "hubs," in which different signals converge and signaling outcome is decided. It is here that critical decisions are made as to whether cargos will be recycled to the plasma membrane (PM), retrotransported to the Golgi, or further trafficked to late endosomes for degradation in lysosomes; in addition, endosomes actively participate to the process through which signals are deconvoluted and rendered to the cell in an understandable form (Spang 2009; Hsu and Prekeris 2010; Jovic et al. 2010).

Endosome trafficking and fusion are regulated by a specific set of molecules, including but not limited to Rab GTPases and SNARE proteins (Brocker et al. 2010; Huotari and Helenius 2011; Jean and Kiger 2012). Recently, in vitro reconstitution of endosome fusion events was achieved using a subset of 17 recombinant human proteins, including RAB5, Rab5 effectors, and SNAREs (Ohya et al. 2009). RAB proteins are not only required for fusion events but they also determine the functional organization of different endosomal compartments, by flagging distinct RAB-containing membrane subdomains both in early and late endosomes (excellently reviewed by Zerial and McBride 2001; Stenmark 2009; Huotari and Helenius 2011; Jean and Kiger 2012). RAB5 and RAB7 specify early and late endosomes, respectively, and the early-to-late endosome transition entails the replacement of RAB5 with RAB7 (Chavrier et al. 1990; Rink et al. 2005). The switch from RAB5positive to RAB7-positive endosomes ("RAB conversion") is achieved via the progressive accumulation of RAB7 at the endosomal membrane, coupled with the parallel removal of RAB5 (Rink et al. 2005; Wandinger-Ness and Zerial 2014), a process conserved throughout evolution (Poteryaev et al. 2010). A similar "maturation mechanism" has been reported for a subset of APPL-endosomes (Zoncu et al. 2009). In a similar vein, Julie Donaldson's group showed that newly formed macropinosomes can be converted directly into early endosomes, through the progressive loss of PIP2 from the vesicles, concomitant to Rab5 recruitment and PIP3 enrichment (Porat-Shliom et al. 2008).

The emerging picture is that of endosomes as extremely dynamic entities. This immediately asks the question of how endosomal dynamics are controlled to respond to changing physiological needs. In the remainder of this section we will review recent advances on how signaling processes and transcriptional programs regulate the endocytic pathway.

\section{Plasticity of the Endocytic Pathway and Control by Signaling Processes}

Endosomal maturation is a tightly regulated process that controls the progressive concentration of specific cargoes at endosomal stations. For example, degradative ligands such as LDL (low-density lipoproteins) become progressively more concentrated in a decreasing number of gradually expanding endosomes migrating from the cell periphery to the center, concomitantly with the replacement of RAB5 by RAB7 (Rink et al. 2005). Importantly, growth factors can influence RAB conversion. Indeed, treatment with EGF (epidermal growth factor) slows down LDL 
transport by activating RAB5 and delaying the RAB5-to-7 conversion (Rink et al. 2005). The heterotrimeric GTP protein (G protein) Gs, a classical mediator of seven-transmembrane or G-protein-coupled receptor (GPCR) signaling, associates with early endosomes and promotes RAB5-to-7 conversion when in its "inactive" (GDP-bound) state (Beas et al. 2012). A similar mode of regulation, in which signaling exerts control over endocytic dynamics, was observed in multivesicular bodies (MVBs). Indeed, EGF stimulation controls both MVB biogenesis, by increasing the number of MVBs per unit of cytoplasm, and inward vesiculation, by increasing the number of intraluminal vesicles (ILVs) per MVB (White et al. 2006).

System-wide analysis of the endocytic pathway further reinforced the idea that the endosomal compartment is dynamically regulated in response to cellular needs (Collinet et al. 2010). Indeed, cells tightly couple the number of EGFpositive endosomes, their size, and intracellular location to cargo concentration in the endosome (Collinet et al. 2010). This precise regulation is expected to impact on endosomal signaling, controlling both quality and strength of signaling outputs. In the same study, it emerged that the regulation of endocytosis by signaling is exerted also at the PM. For instance, various metabolic signaling pathways, such as mTOR, integrin, TGF- $\beta$ R, Notch, and Wnt, significantly alter EGF and/or TF endocytosis at early steps (Collinet et al. 2010). These signals might act either directly on the endocytic machinery or through regulatory feedback loops tightly controlling PM receptor level and availability.

GPCRs also illustrate plasticity of the endocytic pathway at the early stages of the route. Ligand-induced activation of $\beta$-adrenergic receptors promotes their clustering in clathrincoated pits that effect homeostatic control of adrenergic signaling. Receptors present in these coated pits, through interaction of the cytoplasmic tail with proteins associated with the cortical actin cytoskeleton, slow endocytosis of the receptor-containing coated pits (Puthenveedu and von Zastrow 2006). Because adrenergic receptors signal via distinct "waves" of effector activation occurring sequentially from the PM and endosome limiting membrane, such control of early endocytic events by receptors can precisely sculpt the spatiotemporal profile of receptor-elicited cellular signaling (Lohse and Calebiro 2013). Opioid neuropeptide receptors also locally control-coated pit dynamics, and the delay imposed by opioid receptors is effectively "released" by ubiquitination of the same cytoplasmic residues that control the later sorting of receptors within MVBs (Henry et al. 2012). Accordingly, local control of coated pits by opioid receptors reveals an additional "checkpoint" function of cargo control that coordinates the initial endocytosis of receptors with later trafficking events. These studies reinforce the idea that endocytosis cannot be portrayed as a simple transport system from one static compartment to another. Rather, endocytosis is dynamically regulated and rearranged depending on the type and intensity of signaling, and the multiplicity of cargoes engaged.

The plasticity of the endocytic system to environmental cues further emerged through another system-wide approach that investigated context-dependent population phenotypes in endocytosis, using viruses as tools to follow endocytic pathways (Snijder et al. 2009, 2012). These studies showed that clathrin-mediated endocytosis was mostly active in densely populated cell cultures, whereas clathrin-independent pathways (measured as SV40 virus infection) were more efficient in sparsely populated cell cultures. This latter response is achieved through the activation of focal adhesion kinase (FAK) and the consequent modulation of surface levels of the sphingolipid GM1, the receptor for SV40-dependent host cell attachment and entry (Snijder et al. 2009). Thus, these studies revealed that local cell density regulates endocytic pathways.

\section{Transcriptional Programs Regulating the Endocytic Pathway}

An emerging body of evidence is highlighting the existence of highly coordinated transcriptional programs in control of endocytosis (Fig. 1) (also see Settembre and Ballabio 2014). Recent studies have exploited in silico analysis to 
P.P. Di Fiore and M. von Zastrow

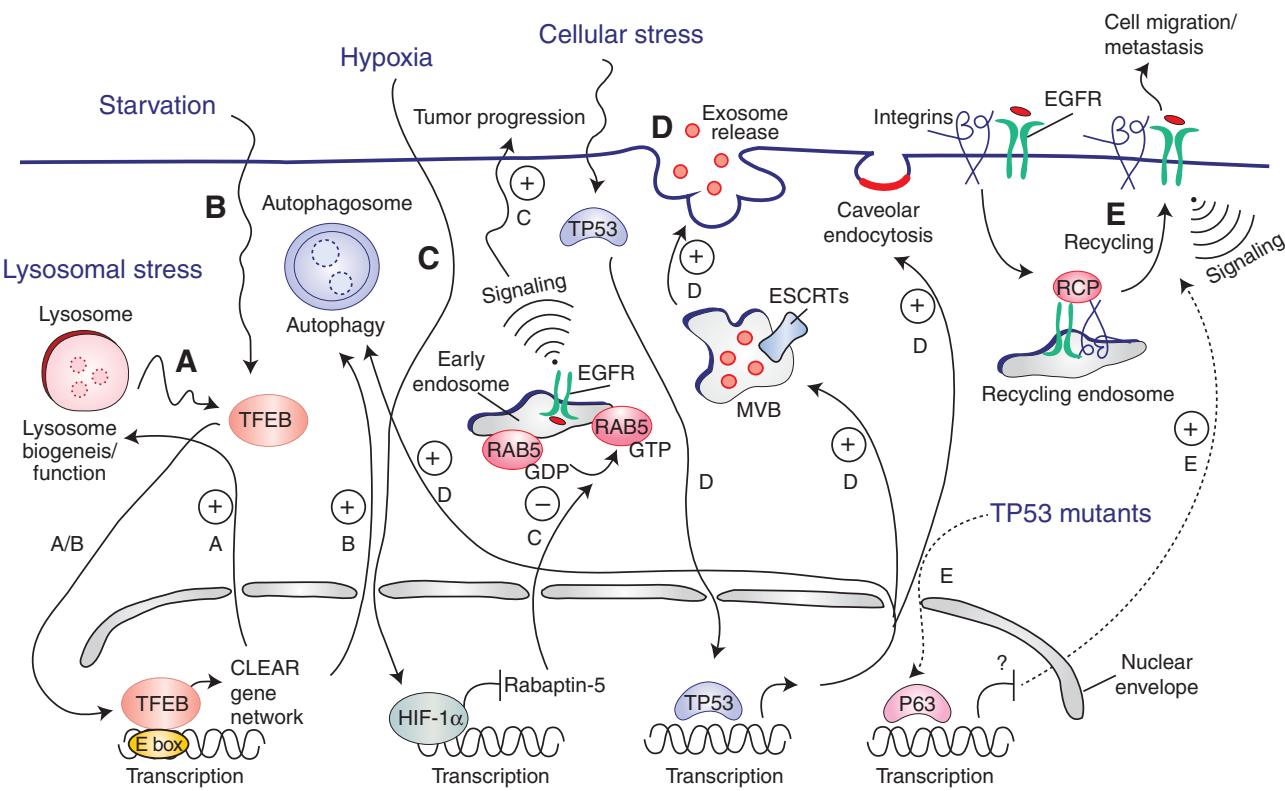

Figure 1. Transcriptional programs controlling endocytosis. Lysosomal stress $(A)$ and/or starvation $(B)$ cause nuclear translocation of the TFEB transcription factor, which binds to the E-box sequence on promoters and induces transcription of a cluster of genes (the "CLEAR network") involved in lysosomal biogenesis/function and autophagy genes, promoting cellular clearance of nondegraded molecules. $(C)$ Activation of HIF1 during hypoxia causes the inhibition of the RABAPTIN-5 gene transcription, inhibition of Rab5 GTP-loading and, consequently, endosomal retention of the EGFR, eventually leading to sustained EGFR signaling from the endosomal station and tumor progression. $(D)$ On different types of cellular stresses, p53 translocates into the nucleus and activates the transcription of genes that play roles at different stations of the endocytic pathway: autophagy genes (e.g., lysosome/autophagosome components), genes involved in exosome release from MVBs (e.g., ESCRT components), and the CAV-1 gene, which stimulates caveolar endocytosis. (E) TP53 mutations found in human cancers exert part of their oncogenic potential through the P63-dependent (transcriptionaldependent) stimulation of RCP-mediated recycling of integrin-EGFR complexes, leading to induced migration and metastasis. The molecular mechanism for this remains unclear.

screen publicly available microarray data for lysosomal gene expression status (Sardiello et al. 2009; Settembre et al. 2013b). The underlying idea was that genes belonging to the same pathway/organelle (the lysosome in this case) should be coexpressed, regulated by common factors, and able to respond to the same signaling and environmental cues. Indeed, it was found that lysosomal genes have a significant tendency to be coexpressed in different tissues and cell types in response to a variety of stimuli and growing conditions (Sardiello et al. 2009). Importantly, a palindromic 10 base site was identified in the promoter region of these genes, a sequence that resembles the so-called "E box," the target site for basic-helix-loop-helix (bHLH) tran- scription factors. A new network, called CLEAR (coordinated lysosomal expression and regulation), was thus identified in its entirety through an in silico bioinformatics analysis. Further experiments in the wet-laboratory identified the transcription factor TFEB as a master regulator of the CLEAR network. TFEB normally binds to the promoter region of lysosomal genes and positively regulates their expression (Sardiello et al. 2009). Under specific conditions, such as when lysosomal dysfunction occurs in lysosomal storage disorders (LSDs), TFEB translocates from the cytoplasm to the nucleus and mediates the coordinated transcriptional activation of lysosomal genes. This stimulates the expression of lysosome biogenesis and function, thus facilitat- 
ing the clearance of nondegraded molecules (Sardiello et al. 2009). These observations illustrate how lysosomal function is tightly and specifically modulated in response to cellular needs (a feature dubbed "lysosomal adaptation").

The CLEAR network contains not only lysosomal proteins but also autophagy substrates (Palmieri et al. 2011). Indeed, a response similar to that observed in LSDs occurs during cell adaptation to starvation, when cells switch to an energy-saving mode of "waste not, want not" by recycling their cellular components to help cater for their metabolic needs (Lieberman et al. 2012). This observation led to the discovery that TFEB also regulates the autophagy pathway via the CLEAR network (Settembre et al. 2011, 2013a). Thus, cells can use the same transcriptional program to regulate distinct, yet mechanistically related, endomembrane-based processes. Thanks to this pioneering work, the concept of plasticity and adaptation of the endocytic system to cellular needs has emerged more clearly than ever, and great attention is now given to the study of transcriptional programs controlling endocytic genes and pathways. Indeed, the CLEAR network is just one example of how the stress-induced transcriptional regulation of endocytic proteins can be used to regulate specific cellular responses; other examples are described below.

Under hypoxia conditions, a transcriptional regulatory loop regulates RAB5 activity. Indeed, the hypoxia-inducible factor HIF1 $\alpha$ was shown to inhibit the transcription of RABAPTIN-5 gene, a critical RAB5 effector (Wang et al. 2009), thus impairing RAB5-mediated early endosome fusion and delaying the endocytic pathway. As a consequence, the resident time of activated EGFR in endosomes is prolonged and signaling is sustained leading to cell proliferation and survival (Wang et al. 2009). In agreement with this mechanism, tumor hypoxia and HIF $1 \alpha$ overexpression generally correlate with an aggressive phenotype and poor patient prognosis (Zhong et al. 1999; Wang et al. 2009). Importantly, primary kidney and breast tumors with strong hypoxic signatures show significantly lower expression of rabaptin-5 mRNA and protein (Wang et al. 2009).
Stress signals activating TP53-dependent transcriptional programs have also been shown to affect the endocytic compartment. Indeed, TP53 regulates genes involved in exosome production, as well as lysosomal membrane proteins required for the induction of the autophagy pathway (Yu et al. 2009b). In addition, TP53 transcriptionally regulates caveolin- 1 , a regulator of caveolar function. As a consequence of TP53 activation, caveolin-1 and EGFR are reported to be internalized concurrently from the PM, and directed to the MVB compartment for degradation (Yu et al. 2009b). In this way, the TP53 program, by regulating the endocytic pathway, could contribute to suppressing cell growth and division in response to stress. Furthermore, it appears that the oncogenic potential of TP53 point mutants found in human cancer may partly lie in their regulatory role within the endocytic pathway (Muller et al. 2009), because it has recently been shown that these mutants not only lose tumor suppression activity, but they also promote invasion and metastasis by inducing RCP (RAB-coupling protein)-mediated recycling of integrins and EGFR, thus sustaining AKT signaling and inducing cell migration (Muller et al. 2009). The mechanism involved is not yet completely understood, but it possibly relies on the inhibition of p63 (a TP53 family member) transcriptional activity.

\section{UNDERSTANDING THE IMPACT OF ENDOCYTOSIS ON CELL PHYSIOLOGY: STUDIES AT THE LEVEL OF REDUCED PHYSIOLOGICAL SYSTEMS}

One approach to exploring the physiological impact of endocytosis is through examining, in ex vivo or in vitro preparations, particular cellular processes that have well-established parallels in vivo. A few examples are briefly described below, based on studies of cardiovascular and nervous system regulation in mammals.

\section{Endocytosis in Sympathetic Control of Cardiac Function}

The sympathetic nervous system exerts physiological control of cardiac contraction strength 
P.P. Di Fiore and M. von Zastrow

and rate by locally releasing catecholamines that activate $\beta 1$ - and $\beta 2$-adrenergic receptors, two closely related GPCRs that are coexpressed on the surface of cardiac myocytes (Fig. 2). $\beta 2$ Adrenergic receptors (B2ARs) have the interesting ability to couple either to Gs or Gi, distinct heterotrimeric $G$ protein mediators that exert opposite effects on cardiac contraction rate.
On initial activation, when most receptors are located in the PM, the heterotrimeric G protein $\mathrm{Gs}$ is activated and cardiac muscle contraction is accelerated. Activated receptors undergo regulated endocytosis followed by recycling to the PM, which is associated with a "switch" of receptor coupling to the distinct $\mathrm{G}$ protein $\mathrm{Gi}$, and a slowing of cardiac muscle contraction. The

Increased contraction

Decreased contraction

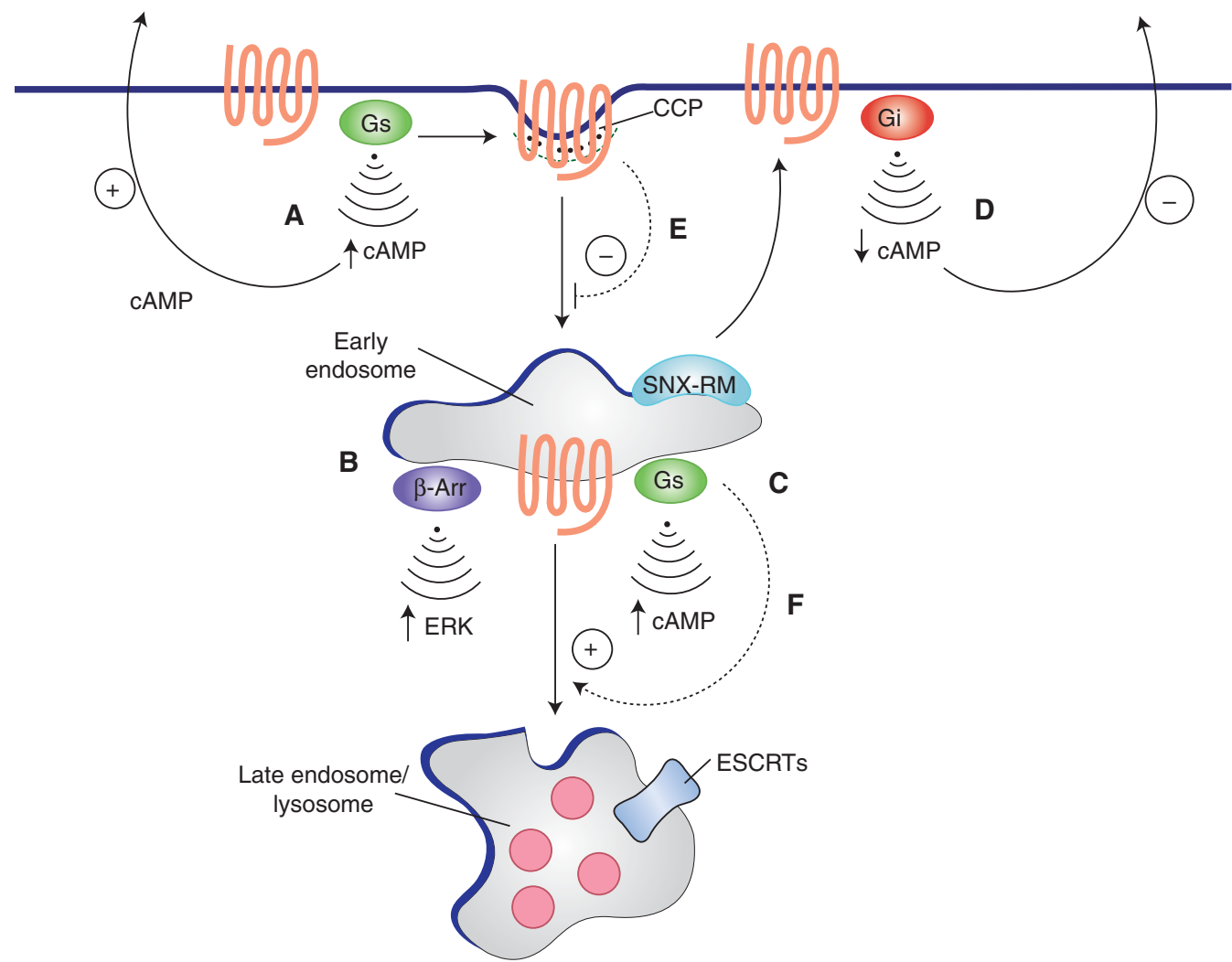

Figure 2. Endocytosis modifies GPCR signaling and vice versa. (A) Activation of the $\beta 2$-adrenergic receptor by catecholamine stimulates adenylyl cyclase through coupling to the heterotrimeric G protein Gs, thereby increasing the cAMP concentration in the cytoplasm. Receptor activation also initiates a process of regulated endocytosis of receptors, mediated by clathrin-coated pits, delivering activated receptors to early endosomes. $(B, C)$ In endosomes receptors are thought to activate noncanonical signaling through the scaffold protein $\beta$ arrestin $\beta$-Arr, leading to activation of MAP kinases $(B)$, and initiate a second "wave" of Gs-mediated activation of adenylyl cyclase that further increases cytoplasmic cAMP concentration $(C)$. Receptors recycle to the PM by engaging a multiprotein sorting machinery, including sorting nexin 27 , and the retromer complex (depicted by SNX-RM in the diagram). (D) On return to the PM, receptors couple to Gi, reducing adenylyl cyclase activity and decreasing cytoplasmic cAMP concentration. In cardiac muscle cells, this series of events causes an acute acceleration (Gs response) followed by deceleration (Gi response) of cardiac contraction (indicated by "+" and "-" arrows in figure). The GPCR-G protein system conversely regulates the endocytic process in at least two ways: (E) $\beta$-Adrenergic receptors locally prolong the surface lifetime of clathrin-coated pits that contain them, and $(F)$ Gs acts in the early endosome membrane to promote endosome maturation through RAB5-to-7 conversion. 
endocytic pathway is proposed to mediate this switch by removing receptors from a region of relative Gs enrichment and inserting recycled receptors into a region of relative $\mathrm{Gi}$ enrichment (Xiang and Kobilka 2003). $\beta$-Adrenergic receptor recycling is dependent on a carboxy-terminal PDZ motif and RAB4, and mediated by receptor engagement with a complex sorting machinery associated with the limiting membrane that includes sorting nexin 27, a WASHArp2/3 actin nucleation complex, and the retromer complex (Lauffer et al. 2010; Puthenveedu et al. 2010; Temkin et al. 2011; Steinberg et al. 2013). Supporting validity of these concepts to higher level ex vivo and in vivo function, disrupting PDZ motif-linked (through sorting nexin 27) engagement of receptors with this machinery selectively abrogates the Gi component of signaling in isolated cardiac myocytes (Xiang and Kobilka 2003). Moreover, inhibiting RAB4 activity in cardiac muscle cells in vivo (using transgenic mice) disrupts catecholamine control of cardiac contractility and leads to heart failure (Odley et al. 2004).

\section{Endocytosis in the Control of Synaptic Neurotransmission}

Fast synaptic transmission occurs at central nervous system (CNS) synapses by exocytic release of neurotransmitter from the presynaptic terminal that, in turn, activates ligand-gated ion channels across the synaptic cleft in the postsynaptic PM. In mammals, fast excitatory neurotransmission is mediated primarily by presynaptic release of glutamate and by subsequent activation of postsynaptic glutamate-gated cation channels, resulting in depolarization of the postsynaptic neuron. In some CNS synapses, such as the extensively studied CA3-CA1 synapse in the hippocampus, the efficacy or strength of excitatory neurotransmission is subject to exquisite regulation through endocytosis and recycling of critical postsynaptic signaling receptors that reduce or increase, respectively, synaptic strength and thereby impact learning (Luscher et al. 1999; Kessels and Malinow 2009). At the CA3-CA1 synapse, the major receptor species subject to rapid regulation by endocytic trafficking is an AMPA-type glutamate-activated cation channel (AMPA receptor), which appears to engage a similar sorting nexin 27 dependent sorting machinery as that engaged by $\beta$-adrenergic receptors (Temkin et al. 2011; Steinberg et al. 2013; Wang et al. 2013). AMPA receptor engagement of this sorting machinery supports efficient recycling of internalized AMPARs and is essential for sustaining or increasing synaptic strength. Disrupting this sorting machinery, conversely, results in inappropriately weak synaptic responses and failure of synapses to potentiate their responsiveness to salient stimuli. Such a disruption of AMPAR recycling was proposed recently to underlie cognitive defects observed in a mouse model of Trisomy 21 or Down syndrome (Wang et al. 2013).

\section{Endocytosis in the Control of Integrated Neuronal Excitability}

In addition to fast synaptic transmission through ligand-gated ion channels, information flow in the nervous system is also affected by slower neuromodulatory processes that affect the electrical excitability of neurons, thus determining how much neurotransmitter will be released presynaptically or how likely it is that activation of a given number of ligand-gated ion channels in the postsynaptic cell will trigger an action potential. Much of this slower neuromodulation is mediated by GPCRs, which are typically expressed on the surface of axons and dendrites outside of, or adjacent to, synaptic specializations. Many of these receptors are regulated by activation-induced endocytosis, and for GPCRs such as the D1-type dopamine receptor and $\mu$ - and $\delta$ - type opioid receptors, this has been clearly shown in vivo (Sternini et al. 1996; Dumartin et al. 1998; Keith et al. 1998; Pradhan et al. 2009). The functional significance of this trafficking remains poorly understood, but the evidence available so far suggests that the consequences may be quite varied. Opioid receptor endocytosis reduces tissue opioid responsiveness (Pradhan et al. 2009) or recovery of tissue responsiveness (Quillinan et al. 2011) after prolonged exposure, and D1 dopamine re- 
ceptor endocytosis increases the acute signaling response, apparently through receptor-mediated initiation of $\mathrm{G}$ protein-linked signaling from endosomes in addition to the PM (Kotowski et al. 2011; see also Morgan et al. 2013 and Cosker and Segal 2014 regarding endocytosis and neuronal function).

\section{UNDERSTANDING THE IMPACT OF ENDOCYTOSIS ON CELL PHYSIOLOGY: INTEGRATION AT THE LEVEL OF TISSUE AND ORGAN HOMEOSTASIS}

The examples described in the previous paragraph highlight how, through the analysis of physiologically relevant systems in vitro, we are developing a stronger sense of how endocytosis impacts on cellular functions and their regulation. A higher level of understanding entails the analysis of how endocytosis impacts the establishment and maintenance of intact tissue and organ homeostasis and on their function. Not surprisingly, model organisms have paved the way for this kind of analysis during development. More recently, in vivo studies in adult mammals have also helped to understand how homeostasis and functionality are maintained by endocytic compartmentalization at the organ level. Here following, we will provide some recent examples of in vivo studies that highlight the importance of the endocytic process in the regulation of tissue differentiation and homeostasis, by concentrating on how endocytosis affects intercellular communication and polarity.

Endocytosis, Spatial Segregation of Signals, and Intercellular Communication

Endocytosis can restrict signaling spatially and temporally within the cell, as shown in vitro for different RTKs ( for a review see Sorkin and von Zastrow 2009; Scita and Di Fiore 2010) and, more recently, as shown unequivocally for GPCRs (Irannejad et al. 2013). This level of regulation controls numerous cell autonomous functions. However, it also impacts profoundly on intercellular communication (excellently reviewed recently in Shilo and Schejter 2011). Many developmental functions are commanded by morphogen gradients, irradiating from signal-sending cells, which differentially instruct target cells, depending on the position of the latter with respect to the gradient. Endocytosis of morphogens by target cells shapes the gradient, as shown for several signaling systems (see, for instance, Kicheva et al. 2007; Yu et al. 2009a; Gonzalez-Gaitan and Jülicher 2014). However, there is now evidence that endocytosis is also critical in the interpretation of the gradient by target cells. By in vivo fluorescence correlation spectroscopy studies, Nowak and coworkers were able to monitor FGF receptor activation and intracellular distribution of the active receptor in zebrafish embryos (Nowak et al. 2011). These experiments revealed that the balance between endosomal versus PM signaling is crucial to interpret morphogen gradients in vivo (FGF8 in this case). Indeed, during zebrafish development, morphogen gradients provide positional information to individual cells within a tissue, thereby determining their fate. Importantly, expression of a Cbl dominant-negative construct, still able to be recruited to the active receptor but impaired in E3 ligase activity, was shown to alter FGFR trafficking, although not by impairing receptor internalization, but rather by affecting its subsequent lysosomal targeting. Although the extracellular FGF8 gradient remained unchanged, the $\mathrm{Cbl}$ dominant negative construct was able to cause the accumulation of active endocytosed FGFR in intracellular compartments, resulting in an extended range of FGF-target gene expression and a broader cellular response to gradient. Thus, the investigators were able to conclude that altered endocytic trafficking influenced the way the morphogen was interpreted by the cell (Nowak et al. 2011).

Recent studies are also highlighting the impact of signal compartmentalization in Wnt signaling. This pathway, which is activated when a member of the Wnt family of ligands (Wingless in Drosophila) binds to a receptor of the Frizzled family and to a coreceptor (frequently LPR6), is involved in many developmental processes and its misregulation causes improper fate specification, tumor formation, and early lethality (Cadigan and Nusse 1997). Initial studies, in Drosophila cells and in the whole animal, re- 
vealed that interference with endocytic routes (obtained by ablation of dynamin or Rab5) reduced the activity of the pathway (Seto and Bellen 2006). It is to be noted that Wnt signaling is operational in paracrine and autocrine situations, rendering it difficult to understand whether the impact of endocytosis is on the "ligand branch" of the pathway or on the "receptor branch." Perhaps not surprisingly, the answer seems to be "on both."

Endocytosis and trafficking play a crucial role in the secretion and pattern distribution of Wnt ligands, thereby regulating their availability (Port and Basler 2010). One critical player in this regard is represented by the multispan integral membrane protein, Wntless (Wls), also known as Evi/Sprinter/GPR177, which is a specific mediator of Wnt ligand secretion and is highly conserved across evolution (Banziger et al. 2006; Bartscherer et al. 2006; Goodman et al. 2006; Fu et al. 2009; Kim et al. 2009). Wls directly binds to Wg (the Drosophila Wnt ligand) - through posttranslational lipidation of the ligand - enabling its transport along the secretory pathway and secretion (Banziger et al. 2006; Bartscherer et al. 2006; Ching and Nusse 2006; Goodman et al. 2006). Endocytosis kicks in with at least two different mechanisms (Koles and Budnik 2012). On the one hand, once exposed on the PM, Wls is continuously internalized and recycled from endosomes to the transGolgi network, thereby allowing further cycles of interaction with $\mathrm{Wg}$ and release of the ligand (Belenkaya et al. 2008; Franch-Marro et al. 2008; Pan et al. 2008; Port et al. 2008; Yang et al. 2008; Kim et al. 2009; Harterink et al. 2011). On the other, studies in the Drosophila neuromuscular junction revealed that $\mathrm{Wg}$ and Wls can be internalized together and then packaged into exosomes that are formed at the level of MVBs. Exosomes are then released in the extracellular space and may facilitate $\mathrm{Wg}$ presentation at the postsynaptic site (Korkut et al. 2009, 2013). This mechanism might explain how the hydrophobic secreted Wg ligand could easily traffic in the extracellular space and reach its target site.

Endocytic-mediated segregation of molecules in distinct compartments also regulates Wnt signaling at the level of the "receptor branch." In unstimulated cells, $\beta$-catenin is phoshorylated by glycogen synthase kinase (GSK-3), a signal for its subsequent polyubiquitination and proteasomal degradation. On Wnt signaling, cytosolic $\beta$-catenin is instead stabilized and translocates to the nucleus to activate specific transcriptional programs (Moon 2005; Clevers and Nusse 2012). The mechanism of $\beta$ catenin stabilization has eluded us until recently, but studies in the Xenopus embryo, now suggest that GSK-3 might be sequestered into the intraluminal vesicles of MVBs, away from its substrates (including $\beta$-catenin), after it is internalized from the PM together with a multiprotein signalosome complex (the LPR6-signalosome) containing Frizzled and LPR6 (Taelman et al. 2010). Sequestration requires the action of two ESCRT components, HRS and VPS4, both of which are required for efficient $\beta$-catenin target gene transcription in vitro and for Wnt-dependent axis duplication in Xenopus embryos (Taelman et al. 2010). Because GSK-3 phosphorylates many substrates, MVB sequestration might represent a global mechanism promoting Wnt-dependent protein stability.

\section{Endocytosis and Cell Polarity: Bidirectional Control in Tissue Morphogenesis}

The establishment of correct cell polarity is critical for tissue morphogenesis. Although the relationships between endomembrane traffic and polarity have been known for a long time, the attention has been mostly concentrated on exocytic pathways. Now evidence is mounting and pointing to a tight and bidirectional control between endocytosis and polarity proteins (Shivas et al. 2010; Eaton and Martin-Belmonte 2014).

A genome-wide RNAi screening in C. elegans identified a general requirement for the polarity proteins PAR6, PAR3, PKC-3 (aPKC), and CDC42 in endocytic trafficking (Balklava et al. 2007). Knockdown of these factors impaired endocytic recycling in C. elegans coelomocytes (terminally differentiated scavenger cells in the body cavity), and altered trafficking in HeLa cells, at different steps depending on the nature of the cargo being transported. The internaliza- 
tion step was blocked for the clathrin-dependent cargo TfR, whereas the recycling step was blocked in case of the clathrin-independent cargo MHC-I (Balklava et al. 2007). The molecular mechanisms through which polarity proteins and complexes might affect endocytosis are not yet clear, and several possibilities have been put forward (reviewed in Shivas et al. 2010). One interesting hypothesis is that they can do so through their interaction with proteins that sit at the crossroads of membrane remodeling and actin dynamics, simultaneously binding regulators of actin dynamics and sensing or inducing membrane curvature. A prototypical example of this kind of protein is the BAR (Bin, Amphiphysin, Rvs) domain superfamily of proteins, which have emerged as important players in membrane-remodeling processes (Rao and Haucke 2011). Proteins belonging to this family include TOCA and CIP4, both of which can remodel the lipid bilayer, and bind to both actin-remodeling factors, such as WASP and WAVEs, and to endocytic proteins, such as dynamin. In Drosophila, the ablation of proteins of the PAR complex (aPKC, PAR6, or CDC42) disrupts endocytosis of E-cadherin (E-cad) and the integrity of adherens junctions (AJs) (Leibfried et al. 2008). The critical player appears here to be CDC42 and its downstream effector CIP4, which binds to WASP and dynamin. Indeed, ablations of CIP4, WASP or dynamin, all phenocopy the loss of CDC42 or of other PAR proteins (Leibfried et al. 2008). Thus, the correct endocytosis of E-cad-required for integrity of AJs and maintenance of polarity-is controlled by PAR proteins, via BAR proteins and their coordination of endocytic events with actin remodeling. Similarly, in C. elegans oocytes, TOCA and CIP4 homologs also act concomitantly on endocytosis and on WAVE and NWASP-dependent actin-dynamics, in this case being needed for correct embryonic morphogenesis to position hypodermal cells and to organize junctional actin and the junction-associated protein AJM-1 (Giuliani et al. 2009).

As mentioned, not only do polarity proteins affect endocytosis, but endocytosis and endosomal sorting were also shown to play a central role in the maintenance of cell polarity. The first evidence in this direction was obtained with the discovery of "transcytosis" in polarized epithelial cells. In this process the correct repertoire of proteins differently sorted to the apical or basolateral surface is not simply obtained by selective exocytic transport, but requires active endocytosis. In other words, some apically polarized proteins are first delivered to the basolateral surface and then endocytosed and redelivered to their final proper apical destination, and vice versa. Accordingly, clathrin was shown to be essential for the maintenance of the polarity of basolateral PM proteins (Deborde et al. 2008). Studies in C. elegans also highlighted the importance of the endocytic system in the maintenance of polarity. Together with the anterior polarity proteins, PAR- 6 and PKC-3, dynamin was shown to participate in the maintenance of anterior polarity in the C. elegans embryo (Nakayama et al. 2009). Rab5 was also involved in the establishment of early embryonic polarity in C. elegans by regulating the localization of PAR6 at the cell cortex and the organization of the actin cytoskeleton (Hyenne et al. 2012). Finally, the presence of a specific apical localization of Rab11-positive recycling endosomes was observed across metazoans, and this was shown to play a prominent role in establishing and maintaining epithelial polarity in C. elegans (Golachowska et al. 2010). In line with this, a genome-wide screening in C. elegans intestine revealed that PAR5 acts as a crucial regulator of apical polarity through its control on Rab11positive endosome localization (Winter et al. 2012).

The importance of the integrity of the endosomal compartment in the maintenance of cell polarity in vivo was further emphasized by work from Marino Zerial's laboratory that exploited an in vivo interfering RNA-based technology to obtain Rab5 ablation in the mouse adult liver (Zeigerer et al. 2012). This study showed that Rab5 is the principal player in the biogenesis of the endolysosomal system in vivo, a process essential for adult liver homeostasis and function. Indeed, depletion of Rab5 reduced the number of early and late endosomes by approximately $80 \%$, and affected the number of lysosomes as a secondary effect. Other components 
previously implicated in endolysosomal biogenesis (like SNAREs and Rab5 effectors) were not altered, suggesting that they are "secondary" endosomal components and cannot per se confer structural and functional identity to their "host" endosome subpopulation. An important consequence of alterations in the endolysosomal system was that apical proteins were not correctly delivered to the bile caniculi, suggesting a role for Rab5 in polarized cargo sorting and in the maintenance of hepatocyte polarity required for liver function.

\section{CONCLUDING REMARKS AND FUTURE DIRECTIONS}

As we continue to uncover the pervasive presence of endocytosis in cell regulation, multiple levels of endocytic-based control emerge. At the circuitry/pathway level, endocytosis and endomembranes selectively switch on and off signals allowing their modulation in space and time. This results in a higher level of governance of cellular functions, whereby many cell autonomous and nonautonomous functions, including proliferation, migration, establishment of polarity, determination of cell fate and/or differentiation, are governed by endocytosis. Ultimately, this translates into endocytic regulation of multicellular plans, during development and in adult life. In turn, and not surprisingly, the existence of bidirectional feedback mechanisms between endocytosis and numerous cellular circuitries bears witness to the deep embedding of endocytosis into cellular and organismal regulation. The deconvolution of this complex network of interactions at multiple levels (circuitry, cells, tissues/organs) represents a frontier in cell biology and is being achieved by the combination of high-throughput and high-resolution studies. It is predictable that increasing understanding of the physiology of the endocytic system will translate into a better understanding of its derailment in pathological conditions.

\section{ACKNOWLEDGMENTS}

Work in the authors' laboratories is supported by grants from the Associazione Italiana per la
Ricerca sul Cancro, the Italian Ministries of Education-University-Research (MIUR) and of Health, the Monzino Foundation, the European Research Council, and the CARIPLO Foundation to PPDF; and by grants from the U.S. National Institutes of Health to M.vZ.

\section{REFERENCES}

* Reference is also in this collection.

Balklava Z, Pant S, Fares H, Grant BD. 2007. Genomewide analysis identifies a general requirement for polarity proteins in endocytic traffic. Nat Cell Biol 9: 10661073.

Banziger C, Soldini D, Schutt C, Zipperlen P, Hausmann G, Basler K. 2006. Wntless, a conserved membrane protein dedicated to the secretion of Wnt proteins from signaling cells. Cell 125: 509-522.

Bartscherer K, Pelte N, Ingelfinger D, Boutros M. 2006. Secretion of Wnt ligands requires Evi, a conserved transmembrane protein. Cell 125: 523-533.

Beas AO, Taupin V, Teodorof C, Nguyen LT, Garcia-Marcos M, Farquhar MG. 2012. Gas promotes EEA1 endosome maturation and shuts down proliferative signaling through interaction with GIV (Girdin). Mol Biol Cell 23: 4623-4634.

Belenkaya TY, Wu Y, Tang X, Zhou B, Cheng L, Sharma YV, Yan D, Selva EM, Lin X. 2008. The retromer complex influences Wnt secretion by recycling wntless from endosomes to the trans-Golgi network. Dev Cell 14: 120131.

* Bissig C, Gruenberg J. 2013. Lipid sorting and multivesicular endosome biogenesis. Cold Spring Harb Perspect Biol 5: a016816.

Brocker C, Engelbrecht-Vandre S, Ungermann C. 2010. Multisubunit tethering complexes and their role in membrane fusion. Curr Biol 20: R943-R952.

* Burd C, Cullen PJ. 2014. Retromer: A master conductor of endosome sorting. Cold Spring Harb Perspect Biol 6: a016774.

Cadigan KM, Nusse R. 1997. Wnt signaling: A common theme in animal development. Genes Dev 11: 32863305 .

Chavrier P, Parton RG, Hauri HP, Simons K, Zerial M. 1990. Localization of low molecular weight GTP binding proteins to exocytic and endocytic compartments. Cell 62: 317-329.

Ching W, Nusse R. 2006. A dedicated Wnt secretion factor. Cell 125: 432-433.

Clevers H, Nusse R. 2012. Wnt/ $\beta$-catenin signaling and disease. Cell 149: 1192-1205.

Collinet C, Stoter M, Bradshaw CR, Samusik N, Rink JC, Kenski D, Habermann B, Buchholz F, Henschel R, Mueller MS, et al. 2010. Systems survey of endocytosis by multiparametric image analysis. Nature 464: 243-249.

* Cosker KE, Segal RA. 2014. Neuronal signaling through endocytosis. Cold Spring Harb Perspect Biol 6: a020669. 
Deborde S, Perret E, Gravotta D, Deora A, Salvarezza S, Schreiner R, Rodriguez-Boulan E. 2008. Clathrin is a key regulator of basolateral polarity. Nature 452: 719723.

Dumartin B, Caille I, Gonon F, Bloch B. 1998. Internalization of D1 dopamine receptor in striatal neurons in vivo as evidence of activation by dopamine agonists. J Neurosci 18: $1650-1661$.

* Eaton S, Martin-Belmonte F. 2014. Cargo sorting in the endocytic pathway: A key regulator of cell polarity and tissue dynamics. Cold Spring Harb Perspect Biol doi: 10.1101/cshperspect.a016899.

Franch-Marro X, Wendler F, Guidato S, Griffith J, BaenaLopez A, Itasaki N, Maurice MM, Vincent JP. 2008 Wingless secretion requires endosome-to-Golgi retrieval of Wntless/Evi/Sprinter by the retromer complex. Nat Cell Biol 10: 170-177.

Fu J, Jiang M, Mirando AJ, Yu HM, Hsu W. 2009. Reciprocal regulation of Wnt and Gpr177/mouse Wntless is required for embryonic axis formation. Proc Natl Acad Sci 106: $18598-18603$.

* Gautreau A, Oguievetskaia K, Ungermann C. 2014. Function and regulation of the endosomal fusion and fission machineries. Cold Spring Harb Perspect Biol doi: 10.1101/ cshperspect.a016832.

Giuliani C, Troglio F, Bai Z, Patel FB, Zucconi A, Malabarba MG, Disanza A, Stradal TB, Cassata G, Confalonieri S, et al. 2009. Requirements for F-BAR proteins TOCA-1 and TOCA-2 in actin dynamics and membrane trafficking during Caenorhabditis elegans oocyte growth and embryonic epidermal morphogenesis. PLoS Genet 5: e1000675.

Golachowska MR, Hoekstra D, van ISC. 2010. Recycling endosomes in apical plasma membrane domain formation and epithelial cell polarity. Trends Cell Biol 20: 618626.

* Gonzalez-Gaitan M, Jülicher F. 2014. The role of endocytosis during morphogenetic signaling. Cold Spring Harb Perspect Biol doi: 10.1101/cshperspect.a016881.

Goodman RM, Thombre S, Firtina Z, Gray D, Betts D, Roebuck J, Spana EP, Selva EM. 2006. Sprinter: A novel transmembrane protein required for $\mathrm{Wg}$ secretion and signaling. Development 133: 4901-4911.

Harterink M, Port F, Lorenowicz MJ, McGough IJ, Silhankova M, Betist MC, van Weering JR, van Heesbeen RG, Middelkoop TC, Basler K, et al. 2011. A SNX3-dependent retromer pathway mediates retrograde transport of the Wnt sorting receptor Wntless and is required for Wnt secretion. Nat Cell Biol 13: 914-923.

* Henne WM, Stenmark H, Emr SD. 2013. Molecular mechanisms of the membrane sculpting ESCRT pathway. Cold Spring Harb Perspect Biol 5: a016766.

Henry AG, Hislop JN, Grove J, Thorn K, Marsh M, von Zastrow M. 2012. Regulation of endocytic clathrin dynamics by cargo ubiquitination. Dev Cell 23: 519-532.

Howes MT, Mayor S, Parton RG. 2010. Molecules, mechanisms, and cellular roles of clathrin-independent endocytosis. Curr Opin Cell Biol 22: 519-527.

Hsu VW, Prekeris R. 2010. Transport at the recycling endosome. Curr Opin Cell Biol 22: 528-534.

Huotari J, Helenius A. 2011. Endosome maturation. EMBO J 30: 3481-3500.
Hyenne V, Tremblay-Boudreault T, Velmurugan R, Grant BD, Loerke D, Labbe JC. 2012. RAB-5 controls the cortical organization and dynamics of PAR proteins to maintain C. elegans early embryonic polarity. PLoS ONE 7: e35286.

Irannejad R, Tomshine JC, Tomshine JR, Chevalier M, Mahoney JP, Steyaert J, Rasmussen SG, Sunahara RK, ElSamad H, Huang B, et al. 2013. Conformational biosensors reveal GPCR signalling from endosomes. Nature 495: 534-538.

Jean S, Kiger AA. 2012. Coordination between RAB GTPase and phosphoinositide regulation and functions. Nat Rev Mol Cell Biol 13: 463-470.

Jovic M, Sharma M, Rahajeng J, Caplan S. 2010. The early endosome: A busy sorting station for proteins at the crossroads. Histol Histopathol 25: 99-112.

Keith DE, Anton B, Murray SR, Zaki PA, Chu PC, Lissin DV, Monteillet-Agius G, Stewart PL, Evans CJ, von Zastrow M. 1998. $\mu$-Opioid receptor internalization: Opiate drugs have differential effects on a conserved endocytic mechanism in vitro and in the mammalian brain. Mol Pharmacol 53: 377-384.

Kessels HW, Malinow R. 2009. Synaptic AMPA receptor plasticity and behavior. Neuron 61: 340-350.

Kicheva A, Pantazis P, Bollenbach T, Kalaidzidis Y, Bittig T, Jülicher F, Gonzalez-Gaitan M. 2007. Kinetics of morphogen gradient formation. Science 315: 521-525.

Kim H, Cheong SM, Ryu J, Jung HJ, Jho EH, Han JK. 2009. Xenopus Wntless and the retromer complex cooperate to regulate XWnt4 secretion. Mol Cell Biol 29: 2118-2128.

* Kirchhausen T, Owen D, Harrison SC. 2014. Molecular structure, function, and dynamics of clathrin-mediated membrane traffic. Cold Spring Harb Perspect Biol doi: 10.1101/cshperspect.a016725.

Koles K, Budnik V. 2012. Exosomes go with the Wnt. Cell Logist 2: 169-173.

Korkut C, Ataman B, Ramachandran P, Ashley J, Barria R, Gherbesi N, Budnik V. 2009. Trans-synaptic transmission of vesicular Wnt signals through Evi/Wntless. Cell 139: 393-404.

Korkut C, Li Y, Koles K, Brewer C, Ashley J, Yoshihara M, Budnik V. 2013. Regulation of postsynaptic retrograde signaling by presynaptic exosome release. Neuron 77: 1039-1046.

Kotowski SJ, Hopf FW, Seif T, Bonci A, von Zastrow M. 2011. Endocytosis promotes rapid dopaminergic signaling. Neuron 71: 278-290.

Lauffer BE, Melero C, Temkin P, Lei C, Hong W, Kortemme T, von Zastrow M. 2010. SNX27 mediates PDZ-directed sorting from endosomes to the plasma membrane. J Cell Biol 190: 565-574.

Leibfried A, Fricke R, Morgan MJ, Bogdan S, Bellaiche Y. 2008. Drosophila Cip4 and WASp define a branch of the Cdc42-Par6-aPKC pathway regulating E-cadherin endocytosis. Curr Biol 18: 1639-1648.

Lieberman AP, Puertollano R, Raben N, Slaugenhaupt S, Walkley SU, Ballabio A. 2012. Autophagy in lysosomal storage disorders. Autophagy 8: 719-730.

Lohse MJ, Calebiro D. 2013. Cell biology: Receptor signals come in waves. Nature 495: 457-458. 
Lupberger J, Zeisel MB, Xiao F, Thumann C, Fofana I, Zona L, Davis C, Mee CJ, Turek M, Gorke S, et al. 2011. EGFR and EphA2 are host factors for hepatitis $C$ virus entry and possible targets for antiviral therapy. Nat Med 17: 589595.

Luscher C, Xia H, Beattie EC, Carroll RC, von Zastrow M, Malenka RC, Nicoll RA. 1999. Role of AMPA receptor cycling in synaptic transmission and plasticity. Neuron 24: 649-658.

* Mayor S, Parton RG, Donaldson JG. 2014. Clathrin-independent pathways of endocytosis. Cold Spring Harb Perspect Biol doi: 10.1101/cshperspect.a016758.

McMahon HT, Boucrot E. 2011. Molecular mechanism and physiological functions of clathrin-mediated endocytosis. Nat Rev Mol Cell Biol 12: 517-533.

Mercer J, Snijder B, Sacher R, Burkard C, Bleck CK, Stahlberg H, Pelkmans L, Helenius A. 2012. RNAi screening reveals proteasome- and Cullin3-dependent stages in vaccinia virus infection. Cell Rep 2: 1036-1047.

* Merrifield CJ, Kaksonen M. 2014. Endocytic accessory factors and regulation of clathrin-mediated endocytosis. Cold Spring Harb Perspect Biol doi: 10.1101/cshper spect.a016733.

Moon RT. 2005. Wnt/ $\beta$-catenin pathway. Sci STKE 2005: $\mathrm{cml}$.

* Morgan JR, Comstra HS, Cohen M, Faundez V. 2013. Presynaptic membrane retrieval and endosome biology: Defining molecularly heterogeneous synaptic vesicles. Cold Spring Harb Perspect Biol 5: a016915.

Muller PAJ, Caswell PY, Doyle B, Iwanicki MP, Tan EH, Karim S, Lukashchuk N, Gillespie DA, Ludwig RL, Gosselin P, et al. 2009. Mutant p53 drives invasion by promoting integrin recycling. Cell 139: 1327-1341.

Nakayama Y, Shivas JM, Poole DS, Squirrell JM, Kulkoski JM, Schleede JB, Skop AR. 2009. Dynamin participates in the maintenance of anterior polarity in the Caenorhabditis elegans embryo. Dev Cell 16: 889-900.

Nowak M, Machate A, Yu SR, Gupta M, Brand M. 2011. Interpretation of the FGF8 morphogen gradient is regulated by endocytic trafficking. Nat Cell Biol 13: 153-158

Odley A, Hahn HS, Lynch RA, Marreez Y, Osinska H, Robbins J, Dorn GW II. 2004. Regulation of cardiac contractility by Rab4-modulated $\beta 2$-adrenergic receptor recycling. Proc Natl Acad Sci 101: 7082-7087.

Ohya T, Miaczynska M, Coskun U, Lommer B, Runge A, Drechsel D, Kalaidzidis Y, Zerial M. 2009. Reconstitution of Rab- and SNARE-dependent membrane fusion by synthetic endosomes. Nature 459: 1091-1097.

Palmieri M, Impey S, Kang H, di Ronza A, Pelz C, Sardiello M, Ballabio A. 2011. Characterization of the CLEAR network reveals an integrated control of cellular clearance pathways. Hum Mol Genet 20: 3852-3866.

Pan CL, Baum PD, Gu M, Jorgensen EM, Clark SG, Garriga G. 2008. C. elegans AP-2 and retromer control Wnt signaling by regulating mig-14/Wntless. Dev Cell 14: $132-$ 139.

Parton RG, del Pozo MA. 2013. Caveolae as plasma membrane sensors, protectors and organizers. Nat Rev Mol Cell Biol 14: 98-112.

Pelkmans L, Fava E, Grabner H, Hannus M, Habermann B, Krausz E, Zerial M. 2005. Genome-wide analysis of hu- man kinases in clathrin- and caveolae/raft-mediated endocytosis. Nature 436: 78-86.

* Piper RC, Dikic I, Lukas G. 2014. Ubiquitin-dependent sorting in endocytosis. Cold Spring Harb Perspect Biol 6: a016808.

Porat-Shliom N, Kloog Y, Donaldson JG. 2008. A unique platform for $\mathrm{H}$-Ras signaling involving clathrin-independent endocytosis. Mol Biol Cell 19: 765-775.

Port F, Basler K. 2010. Wnt trafficking: New insights into Wnt maturation, secretion and spreading. Traffic 11: 1265-1271.

Port F, Kuster M, Herr P, Furger E, Banziger C, Hausmann G, Basler K. 2008. Wingless secretion promotes and requires retromer-dependent cycling of Wntless. Nat Cell Biol 10: $178-185$.

Poteryaev D, Datta S, Ackema K, Zerial M, Spang A. 2010. Identification of the switch in early-to-late endosome transition. Cell 141: 497-508.

Pradhan AA, Becker JA, Scherrer G, Tryoen-Toth P, Filliol D, Matifas A, Massotte D, Gaveriaux-Ruff C, Kieffer BL. 2009. In vivo $\delta$ opioid receptor internalization controls behavioral effects of agonists. PLoS ONE 4: e5425.

Puthenveedu MA, von Zastrow M. 2006. Cargo regulates clathrin-coated pit dynamics. Cell 127: 113-124.

Puthenveedu MA, Lauffer B, Temkin P, Vistein R, Carlton P, Thorn K, Taunton J, Weiner OD, Parton RG, von Zastrow M. 2010. Sequence-dependent sorting of recycling proteins by actin-stabilized endosomal microdomains. Cell 143: $761-773$.

Quillinan N, Lau EK, Virk M, von Zastrow M, Williams JT. 2011. Recovery from $\mu$-opioid receptor desensitization after chronic treatment with morphine and methadone. J Neurosci 31: 4434-4443.

Rao Y, Haucke V. 2011. Membrane shaping by the Bin/amphiphysin/Rvs (BAR) domain protein superfamily. Cell Mol Life Sci 68: 3983-3993.

Rink J, Ghigo E, Kalaidzidis Y, Zerial M. 2005. Rab conversion as a mechanism of progression from early to late endosomes. Cell 122: 735-749.

Sandvig K, Pust S, Skotland T, van Deurs B. 2011. Clathrinindependent endocytosis: Mechanisms and function. Curr Opin Cell Biol 23: 413-420.

Sardiello M, Palmieri M, di Ronza A, Medina DL, Valenza M, Gennarino VA, Di Malta C, Donaudy F, Embrione V, Polishchuk RS, et al. 2009. A gene network regulating lysosomal biogenesis and function. Science 325: 473477.

Scita G, Di Fiore PP. 2010. The endocytic matrix. Nature 463: 464-473.

Seto ES, Bellen HJ. 2006. Internalization is required for proper Wingless signaling in Drosophila melanogaster. $J$ Cell Biol 173: 95-106.

* Settembre C, Ballabio A. 2014. Lysosomal adaptation: How the lysosome responds to external cues. Cold Spring Harb Perspect Biol doi: 10.1101/cshperspect.a016907.

Settembre C, Di Malta C, Polito VA, Garcia Arencibia M, Vetrini F, Erdin S, Erdin SU, Huynh T, Medina D, Colella P, et al. 2011. TFEB links autophagy to lysosomal biogenesis. Science 332: 1429-1433.

Settembre C, De Cegli R, Mansueto G, Saha PK, Vetrini F Visvikis O, Huynh T, Carissimo A, Palmer D, Jurgen 
P.P. Di Fiore and M. von Zastrow

Klisch T, et al. 2013a. TFEB controls cellular lipid metabolism through a starvation-induced autoregulatory loop. Nat Cell Biol 15: 647-658.

Settembre C, Fraldi A, Medina DL, Ballabio A. 2013b. Signals from the lysosome: A control centre for cellular clearance and energy metabolism. Nat Rev Mol Cell Biol 14: 283-296.

Shilo BZ, Schejter ED. 2011. Regulation of developmental intercellular signalling by intracellular trafficking. $E M B O$ J 30: 3516-3526.

Shivas JM, Morrison HA, Bilder D, Skop AR. 2010. Polarity and endocytosis: Reciprocal regulation. Trends Cell Biol 20: $445-452$.

Sigismund S, Confalonieri S, Ciliberto A, Polo S, Scita G, Di Fiore PP. 2012. Endocytosis and signaling: Cell logistics shape the eukaryotic cell plan. Physiol Rev 92: 273-366.

Snijder B, Sacher R, Ramo P, Damm EM, Liberali P, Pelkmans L. 2009. Population context determines cell-to-cell variability in endocytosis and virus infection. Nature 461: 520-523.

Snijder B, Sacher R, Ramo P, Liberali P, Mench K, Wolfrum N, Burleigh L, Scott CC, Verheije MH, Mercer J, et al. 2012. Single-cell analysis of population context advances RNAi screening at multiple levels. Mol Syst Biol 8: 579.

Sorkin A, von Zastrow M. 2009. Endocytosis and signalling: Intertwining molecular networks. Nat Rev Mol Cell Biol 10: 609-622.

Spang A. 2009. On the fate of early endosomes. Biol Chem 390: $753-759$.

Steinberg F, Gallon M, Winfield M, Thomas EC, Bell AJ, Heesom KJ, Tavare JM, Cullen PJ. 2013. A global analysis of SNX27-retromer assembly and cargo specificity reveals a function in glucose and metal ion transport. Nat Cell Biol 15: 461-471.

Stenmark H. 2009. Rab GTPases as coordinators of vesicle traffic. Nat Rev Mol Cell Biol 10: 513-525.

Sternini C, Spann M, Anton B, Keith DE Jr, Bunnett NW, von Zastrow M, Evans C, Brecha NC. 1996. Agonist-selective endocytosis of $\mu$ opioid receptor by neurons in vivo. Proc Natl Acad Sci 93: 9241-9246.

Taelman VF, Dobrowolski R, Plouhinec JL, Fuentealba LC, Vorwald PP, Gumper I, Sabatini DD, De Robertis EM 2010. Wnt signaling requires sequestration of glycogen synthase kinase 3 inside multivesicular endosomes. Cell 143: $1136-1148$.

Temkin P, Lauffer B, Jager S, Cimermancic P, Krogan NJ, von Zastrow M. 2011. SNX27 mediates retromer tubule entry and endosome-to-plasma membrane trafficking of signalling receptors. Nat Cell Biol 13: 715-721.

* Wandinger-Ness A, Zerial M. 2014. Rab proteins and the compartmentalization of the endosomal system.
Cold Spring Harb Perspect Biol doi: 10.1101/cshperspect.a022616.

Wang Y, Roche O, Yan MS, Finak G, Evans AJ, Metcalf JL, Hast BE, Hanna SC, Wondergem B, Furge KA, et al. 2009. Regulation of endocytosis via the oxygen-sensing pathway. Nat Med 15: 319-324.

Wang X, Zhao Y, Zhang X, Badie H, Zhou Y, Mu Y, Loo LS, Cai L, Thompson RC, Yang B, et al. 2013. Loss of sorting nexin 27 contributes to excitatory synaptic dysfunction by modulating glutamate receptor recycling in Down's syndrome. Nat Med 19: 473-480.

White IJ, Bailey LM, Aghakhani MR, Moss SE, Futter CE. 2006. EGF stimulates annexin 1-dependent inward vesiculation in a multivesicular endosome subpopulation. EMBO J 25: 1-12.

Winter JF, Hopfner S, Korn K, Farnung BO, Bradshaw CR, Marsico G, Volkmer M, Habermann B, Zerial M. 2012. Caenorhabditis elegans screen reveals role of PAR-5 in RAB-11-recycling endosome positioning and apicobasal cell polarity. Nat Cell Biol 14: 666-676.

Xiang Y, Kobilka B. 2003. The PDZ-binding motif of the $\beta 2$ adrenoceptor is essential for physiologic signaling and trafficking in cardiac myocytes. Proc Natl Acad Sci 100: 10776-10781.

Yang PT, Lorenowicz MJ, Silhankova M, Coudreuse DY, Betist MC, Korswagen HC. 2008. Wnt signaling requires retromer-dependent recycling of MIG-14/Wntless in Wnt-producing cells. Dev Cell 14: 140-147.

Yu SR, Burkhardt M, Nowak M, Ries J, Petrasek Z, Scholpp S, Schwille P, Brand M. 2009a. Fgf8 morphogen gradient forms by a source-sink mechanism with freely diffusing molecules. Nature 461: 533-536.

Yu X, Riley T, Levine AJ. 2009b. The regulation of the endosomal compartment by $\mathrm{p} 53$ the tumor suppressor gene. FEBS J 276: 2201-2212.

Zeigerer A, Gilleron J, Bogorad RL, Marsico G, Nonaka H, Seifert S, Epstein-Barash H, Kuchimanchi S, Peng CG, Ruda VM, et al. 2012. Rab5 is necessary for the biogenesis of the endolysosomal system in vivo. Nature 485: 465470.

Zerial M, McBride H. 2001. Rab proteins as membrane organizers. Nat Rev Mol Cell Biol 2: 107-117.

Zhong H, De Marzo AM, Laughner E, Lim M, Hilton DA, Zagzag D, Buechler P, Isaacs WB, Semenza GL, Simons JW. 1999. Overexpression of hypoxia-inducible factor $1 \alpha$ in common human cancers and their metastases. Cancer Res 59: 5830-5835.

Zoncu R, Perera RM, Balkin DM, Pirruccello M, Toomre D, De Camilli P. 2009. A phosphoinositide switch controls the maturation and signaling properties of APPL endosomes. Cell 136: 1110-1121. 


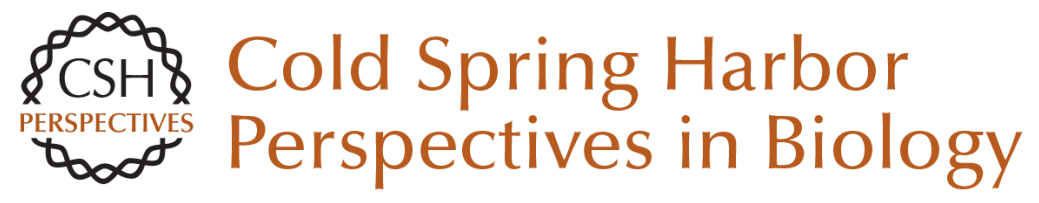

\section{Endocytosis, Signaling, and Beyond}

Pier Paolo Di Fiore and Mark von Zastrow

Cold Spring Harb Perspect Biol 2014; doi: 10.1101/cshperspect.a016865

Subject Collection Endocytosis

\section{Endocytosis: Past, Present, and Future} Sandra L. Schmid, Alexander Sorkin and Marino Zerial

Rab Proteins and the Compartmentalization of the Endosomal System Angela Wandinger-Ness and Marino Zerial

Cargo Sorting in the Endocytic Pathway: A Key Regulator of Cell Polarity and Tissue Dynamics Suzanne Eaton and Fernando Martin-Belmonte

Unconventional Functions for Clathrin, ESCRTs, and Other Endocytic Regulators in the Cytoskeleton, Cell Cycle, Nucleus, and Beyond: Links to Human Disease

Frances M. Brodsky, R. Thomas Sosa, Joel A. Ybe, et al.

Endocytosis of Viruses and Bacteria Pascale Cossart and Ari Helenius

Lysosomal Adaptation: How the Lysosome Responds to External Cues Carmine Settembre and Andrea Ballabio

Reciprocal Regulation of Endocytosis and Metabolism

Costin N. Antonescu, Timothy E. McGraw and Amira Klip

Endocytosis and Autophagy: Exploitation or Cooperation?

Sharon A. Tooze, Adi Abada and Zvulun Elazar
Imaging and Modeling the Dynamics of

Clathrin-Mediated Endocytosis

Marcel Mettlen and Gaudenz Danuser

Endocytic Accessory Factors and Regulation of

Clathrin-Mediated Endocytosis

Christien J. Merrifield and Marko Kaksonen

The Complex Ultrastructure of the Endolysosomal

System Judith Klumperman and Graça Raposo

The Biogenesis of Lysosomes and

Lysosome-Related Organelles

J. Paul Luzio, Yvonne Hackmann, Nele M.G.

Dieckmann, et al.

Endocytosis, Signaling, and Beyond Pier Paolo Di Fiore and Mark von Zastrow

Clathrin-Independent Pathways of Endocytosis Satyajit Mayor, Robert G. Parton and Julie G. Donaldson

The Role of Endocytosis during Morphogenetic Signaling Marcos Gonzalez-Gaitan and Frank Jülicher

Role of Endosomes and Lysosomes in Human Disease

Frederick R. Maxfield

For additional articles in this collection, see http://cshperspectives.cshlp.org/cgi/collection/

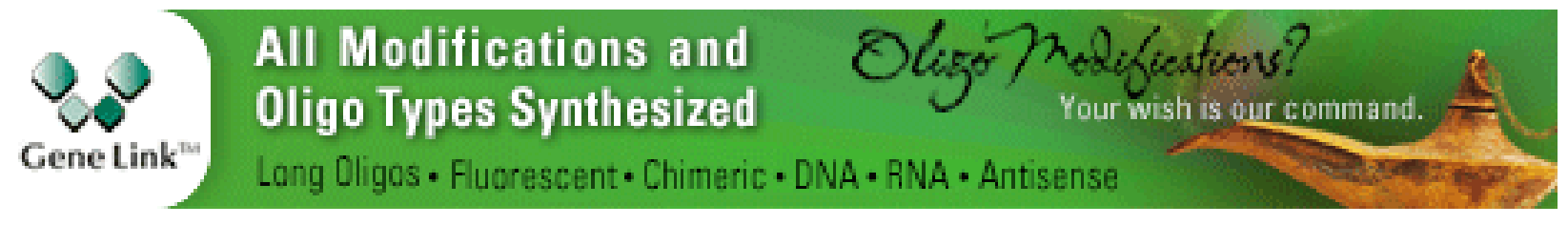

Copyright @ 2014 Cold Spring Harbor Laboratory Press; all rights reserved 
For additional articles in this collection, see http://cshperspectives.cshlp.org/cgi/collection/

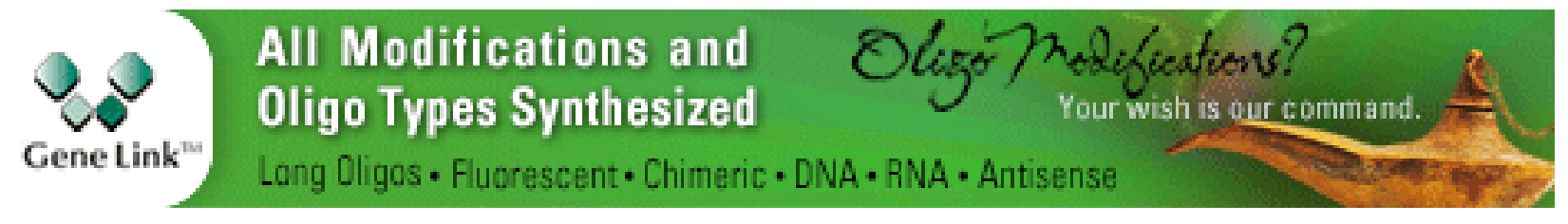

Copyright @ 2014 Cold Spring Harbor Laboratory Press; all rights reserved 